\title{
Development of the wide-swath and high-resolution optical imager onboard Advanced Optical Satellite (ALOS-3)
}

Hidenori Watarai, Haruyoshi Katayama, Tomoya Niwa, and Masakazu Sagisaka

Japan Aerospace Exploration Agency

Tsukuba Space Center

10/10/2018 ICSO@ Chania 
- Introduction

- ALOS-3, a successor of Advanced Land Observing Satellite (ALOS) "DAICHI"

- Wide-swath and High-resolution Optical Imager (WISH)

- Specifications and final design at the CDR

- Current development status of WISH

- Manufacturing of mirrors

- Integration flow of the optics and its demonstration

- Summary and future schedule 


\section{IXXA Specifications of ALOS-3 satellite system}

\begin{tabular}{|c|c|c|}
\hline & Item & Specifications \\
\hline & Type & Sun synchronous sub-recurrent orbit \\
\hline Ohasi & Altitude & 669 km \\
\hline UIDIt & LST & 10:30 AM \\
\hline & Revisit time & 35 days (sub-cycle is approx. 3 days) \\
\hline Onboar & Imager & Wide-swath and High-resolution Imager (WISH) \\
\hline GSD at & adir & $\mathrm{Pa}: 0.8 \mathrm{~m} \quad \mathrm{Mu}: 3.2 \mathrm{~m}$ \\
\hline Swath & & $70 \mathrm{~km}$ \\
\hline Maximı & Observation time & $>10$ min per one orbital path \\
\hline Missior & lata rate & approx. 4 Gbps (Pa 1/4, Mu 1/3 data compression) \\
\hline Commı & ications & $\begin{array}{l}\text { Ka-band: > } 1.6 \mathrm{Gbps} \\
\text { X-band: > } 0.8 \mathrm{Gbps} \\
\text { Optical data transmission via the optical relay satellite }\end{array}$ \\
\hline Mass & & $2,700 \mathrm{~kg}$ \\
\hline Size & & $5 \mathrm{~m} \times 3.5 \mathrm{~m} \times 16 \mathrm{~m}$ across the deployed solar array \\
\hline Missior & ife & $>7$ years \\
\hline
\end{tabular}




\section{JAFA Wide-Swath and High-resolution Imager (WISH)}



- We employ an off-axis four mirror anastigmatic (FMA) telescope to achieve both wide-swath \& high-resolution.

- This FMA is basically same with off-axis TMA. But the forth mirror (M4) has a slight curvature. It enable us to make the optics compact. Total length of telescope is $30 \%$ smaller than that of conventional TMA.

- The surface shape of M1, M3 and M4 are sixth order aspherical. M2 has conic surface. 


\section{Specifications of WISH}

\begin{tabular}{|c|c|c|}
\hline Item & Specifications & Memo \\
\hline Optics & Off-axis Four Mirror Anastigmat & Basically same with TMA \\
\hline Bands & $\begin{array}{ll}\frac{\mathrm{Pa}}{\mathrm{Mu}} 0.52-0.76 \mu \mathrm{m} \\
\frac{\mathrm{b}}{\text { band } 1} & 0.40-0.45 \mu \mathrm{m} \text { (Coastal) } \\
\text { band } 2 & 0.45-0.50 \mu \mathrm{m} \text { (Blue) } \\
\text { band } 3 & 0.52-0.60 \mu \mathrm{m} \text { (Green) } \\
\text { band } 4 & 0.61-0.69 \mu \mathrm{m} \text { (Red) } \\
\text { band } 5 & 0.69-0.74 \mu \mathrm{m} \text { (RedEdge) } \\
\text { band } 6 & 0.76-0.89 \mu \mathrm{m} \text { (NIR-1) }\end{array}$ & $\begin{array}{l}\text { Coastal and RedEdge are } \\
\text { added to four band of ALOS } \\
\text { AVNIR-2 }\end{array}$ \\
\hline IFOV & $\begin{array}{l}\mathrm{Pa}:<0.247 \text { arcsec } \\
\mathrm{Mu}:<0.987 \text { arcsec }\end{array}$ & $\begin{array}{l}\text { Correspond to } 0.8 \mathrm{~m}(\mathrm{~Pa}) \text { and } \\
3.2 \mathrm{~m}(\mathrm{Mu}) \text { from the nominal } \\
\text { orbit }\end{array}$ \\
\hline Field of view & $>6.0$ degree & $=70 \mathrm{~km}$ at nadir \\
\hline MTF @ Nyquist & $\mathrm{Pa}:>0.1 \quad \mathrm{Mu}:>0.2$ & over the whole field of view \\
\hline Dynamic Range & 11 bit & improved from 8 bit of ALOS \\
\hline Detectors & $\begin{array}{l}\text { Pa: } 128 \text { stages TDI, } 8 \mu \mathrm{m} \text { pitch, } 8192 \text { pixel } \\
\text { Mu: } 32 \text { stages TDI, } 32 \mu \mathrm{m} \text { pitch, } 2048 \text { pixel }\end{array}$ & $\begin{array}{l}12 \mathrm{CCD} \text { for both of } \mathrm{Pa} \& \mathrm{Mu} \text { are } \\
\text { assembled on a focal plane }\end{array}$ \\
\hline
\end{tabular}




\section{IXXAA Mechanical design of WISH}

\section{Focus Adjustment Mechanism (FAM) \\ $\mathrm{w} /$ secondary mirror (M2) assy}

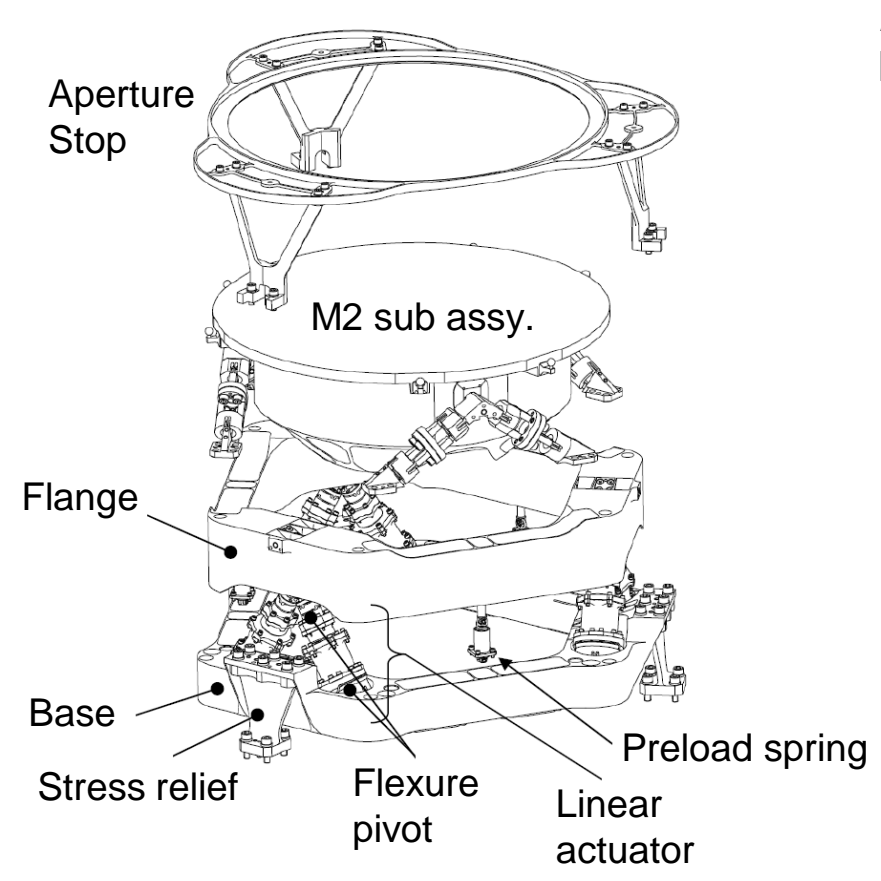

FAM has the ability to adjust the alignment of M2 with 5 DOF.


The vibration test by using the engineering / structural model has been completed with no serious problem. 


\section{Mirror manufacturing team}



CLEARCERAM®-Z

a glass-ceramic with an ultra-low thermal expansion coefficient
Optical design, Mechanical design, Lightweight and R-shape processing

Photo: Primary Mirror (EM) Outline: $100 \mathrm{~cm} \times 70 \mathrm{~cm} \times 16 \mathrm{~cm}$ Weight: $45 \mathrm{~kg}$

\section{Canon}



Optical design support

Grinding, polishing and Ag coating 


\section{WXA Mirror manufacturing process (1/3)}

Canon Super-Smooth Polisher (CSSP)


Front view of the primary mirror (EM)
Mirror assembly



\section{A-Ruler}

The high-precision free-form measuring machine developed by Canon Inc.

- a contact type measuring device

- Accuracy : < $10 \mathrm{~nm}$ rms

- Measuring area : 1000 x $500 \mathrm{~mm}$



(c) Canon Inc. 


\section{LKJA Mirror manufacturing process (2/3)}


(1) $8.4 \mathrm{~nm}$ RMS

(2) $7.1 \mathrm{~nm}$ RMS

(3) $6.6 \mathrm{~nm}$ RMS

(4) $7.2 \mathrm{~nm}$ RMS

(5) $7.0 \mathrm{~nm}$ RMS

(6) $6.5 \mathrm{~nm}$ RMS

(7) $5.9 \mathrm{~nm}$ RMS

(8) $6.7 \mathrm{~nm}$ RMS

Measured surface error of M3 PFM within a $\$ 271 \mathrm{~mm}$ local circle (foot print on M3). These values are good enough for total WFE budget.

The fine polishing of other mirrors are also on going. 


\section{KXJA Mirror manufacturing process (3/3)}


Surface error measurement of the primary mirror (EM) using a laser interferometer and a computer generated hologram (CGH). Right picture shows mirror and its stage that can rotate 180 deg with respect to the direction of gravity to estimate the mirror surface shape in zero gravity environment.

All the mirrors are designed so that the gravity deformation becomes the smallest when the $y$-axis is aligned with the gravity direction.

The system is adopted to measuring M1 and M3. 


\section{Integration flow of the optics}






\section{Summary and future schedule}

- JAXA has been developing the next land observing satellite (ALOS-3) and Wide-Swath and High-resolution Optical Imager (WISH) since FY 2016.

- The development of WISH is in the final stage of critical design phase. Development test using the engineering model or the structural model have almost been completed with no critical problem.

$\checkmark$ Final design of WISH, manufacturing process of mirrors and the integration flow of the optics were shown.

- The demonstration work of the high accuracy assembly of WISH's optics has been continued.

PFM manufacturing of WISH and subsequent PFT would be conducted about a year from now. WISH would be delivered to the satellite system by the middle of FY 2019.

ALOS-3 equipped with WISH would be launched by H-IIA rocket in FY 2020. 

Backup Slide 


\section{Structural model (SM)}



Structural model (SM) of WISH. Vibration tests were carried out using this model. 




Panchromatic band $8 \mu \mathrm{m}$ pitch with micro-lens 8092 pixel $x 128$ stage TDI 8 readout channel



Multispectral band $32 \mu \mathrm{m}$ pitch (no micro-lens) 2048 pixel $x 32$ stage TDI 6 band

w/ on-chip clock driver \& correlated double sampling (CDS) circuit 